\title{
Framing Gender Inequality: Millennium Development Goal 3 and the Post-2015 Agenda
}

\author{
William Lutwyche
}

I will personally ensure that the fight for the empowerment of women is at the heart of the international process I am co-chairing to renew the Millennium Development Goals.

UK Prime Minister David Cameron, July 2012

\section{Abstract}

Millennium Development Goal 3 (MDG3) has become the universal barometer by which global gender equality progress is judged. This essay argues that the framing of MDG3 and its corresponding indicators of progress obfuscate the complexities of gender equality. Whilst the reductionist nature of MDG3 has allowed for increased awareness of the issue, it de-contextualises and obfuscates the complex nature of gender inequality. This argument is illustrated through tracing the use of the three MDG3 indicators of progress: (i) to eliminate gender disparity in educational enrolment; (ii) increase the share of women in non-agricultural wage employment; and, (iii) the proportion of seats held by women in national parliaments. In response to the criticisms of oversimplified framing of MDG3, this essay analyses how including a consideration of gender-based violence and a twin-track approach in the post-2015 era could, at least in part, address these issues. The current reframing of gender equality in the post-2015 era fails to directly address these matters. Broadly, the analysis in this essay fundamentally brings into question the legitimacy of the progress proclaimed as part of MDG3.

\section{Introduction}

Since the Millennium Development Goals (MDGs) were adopted in 2000, there has been an unprecedented level of public, political and financial support for gender equality and empowerment in developing nations. As the 2015 target 
date for achieving the MDGs approaches, a number of processes are underway within the United Nations (UN) system and its member states, academia, policymakers and civil society to formulate a new global development agenda. For gender and development, this proposed global framework represents another chance - perhaps the only one - to secure the future of gender equality in development discourse and practice. In this context it is necessary to ask, has gender inequality and empowerment been sufficiently represented in the current framework?

Whilst gender is inherent in other MDGs, this essay is limited to examining MDG3, which endeavours to 'promote gender equality and empower women'. This essay argues that the framing of MDG3 and its corresponding indicators of progress obfuscate the complexities of gender equality and development practice. While the reductionist nature of MDG3 has allowed for increased awareness, it de-contextualises and obfuscates the complex nature of gender inequality. This conclusion fundamentally questions the legitimacy of progress proclaimed under MDG3. The essay is divided into three sections. Firstly, a brief background and context to the debate is given by introducing the MDGs and MDG3. The second section examines each indicator of progress underlying MDG3 and how gender equality and empowerment are framed to measure progress through gender disparity in educational enrolment, non-agricultural wage employment and the percentage of women in national parliaments. The third section critiques gender-based violence as an essential variable missing from MDG3. It is evaluated and considered for inclusion in a post-2015 framework. Following this, the essay examines the recently proposed macrolevel twin-track approach to achieving gender equality. This strategy envisions a reinvigorated stand-alone goal on gender equality in conjunction with gender being mainstreamed across all new post-2015 objectives. These points of analysis clearly demonstrate that the MDG framework is an inadequate reflection of global progress on gender inequality. A gendered post-2015 framework should encompass improved sex disaggregated data collection and redefined progress indicators that can be applied and evaluated universally.

\section{Background}

In September 2000, leaders from 189 countries, including 147 heads of state and government, gathered at the UN and unanimously adopted the Millennium Declaration - a commitment to a future based on peace, prosperity and justice (UN 2000). To achieve this, countries endorsed the MDGs, a set of eight goals aimed at development and poverty reduction, with quantitative targets to be achieved by 2015. The goals are based on income deprivation, hunger, gender equality, education, the environment, health and global partnerships for 
development. They unequivocally present the alleviation of global poverty as an ethical imperative for all states and international organisations (Hulme \& Fukuda-Parr 2009). By 2001 the MDG framework of eight goals included 18 targets and 48 progress indicators. The MDGs are now commonly accepted as the universal framework for measuring development progress globally, nationally and regionally (Clemens, Kenny \& Moss 2007; Fukuda-Parr, Greenstein \& Stewart 2013; UN 2005: 10). Accordingly, development progress associated with gender equality is measured in line with the indicators underpinning MDG3.

It is universally agreed that the world is a long way from achieving gender equality. The MDGs, however, have been cited as a 'powerful stimulus' for raising the profile and importance of alleviating gender inequality globally (Organisation for Economic Co-operation and Development (OECD) 2013). Scaling up investment and action on gender equality has the dual advantage of addressing widespread inequality and accelerating development progress overall (United Nations Development Fund for Women (UNIFEM) 2012). Given its importance, how MDG3 and the forthcoming post-2015 agenda frame gender equality is critical to ensuring development effectiveness and sustainable change. Kabeer (2005), however, questions the meaning of gender equality and empowerment, and how it is framed through a goal-oriented strategy. Additionally, questions have been raised regarding the sufficiency of using only one educational goal and four indicators to measure progress on global gender equality (Elson \& Balakrishnan 2012). The next section of this essay unpacks this analysis and shows that MDG3 is framed to de-contextualise gender inequality in order to incite mobilisation and awareness. This approach comes at the cost of obfuscating the reality of development, bringing into question any progress cited under MDG3.

\section{The Framing of MDG3}

The MDGs have been useful in drawing attention to pervasive gender-based deprivation in the developing world and the need for a coordinated global effort to address this prevalent issue. The framing mechanisms used to measure MDG3 progress have, however, been extensively criticised. As stated previously, MDG3's progress is framed through one target: 'to eliminate gender disparity in primary and secondary education, preferably by 2005, and at all level of education no later than 2015.' This target was defined as the ratio of girls' to boys' enrolment in primary, secondary and tertiary education. Three other indicators were added to MDG3: the ratio of literate females to males among 15-25 year olds, the share of women in non-agricultural wage employment and the proportion of seats held by women in national parliaments. This section determines the extent to which educational enrolment and its successive indicators sufficiently 
represent global progress on gender equality and empowerment. It is important to first define these terms and establish a criterion against which the indicators of progress can be measured.

\section{Gender Inequality and Empowerment}

The UN (2012) defines gender inequality in terms of capabilities (education, health and nutrition) and opportunities (economic and decision-making). Similarly, the World Bank (2011) defines gender inequality through equality under the law, equality of opportunity and equality of voice. Grown et al. (2003) combine these two approaches and suggest two domains for measuring the equality of women in relation to men. Firstly, the 'capabilities' domain refers to basic human abilities as measured through education, health and nutrition. This domain reflects the MDG3 indicators of gender disparity in educational enrolment rates. Secondly, the 'access to resources and opportunities' domain refers to the opportunity to use or apply the aforementioned capabilities through access to economic assets and resources (Grown et al. 2003: 3). This domain reflects the third indicator of women in wage employment in the non-agricultural sector. Women's empowerment is closely related to, but goes beyond, gender equality, encompassing not just women's condition relative to men's, but also their 'agency' and power to make choices (Smee \& Woodroffe 2013).

Malhorta et al. (2002) and Kabeer (2005) assert that empowerment should be measured through the ability to make choices. Put simply, Kabeer (2001, cited in Malhorta, et al. 2002: 6) defines it as, 'The expansion in people's ability to make strategic life choices in a context where this ability was previously denied to them.' This definition is useful as it contains two elements that distinguish empowerment from other related concepts, such as equality: firstly, the idea of process and change from a condition of disempowerment and, secondly, that of human agency and choice. Kabeer (2005: 15) argues that the empowerment of women in MDG3 should be centred on forms of 'transformative agency'. These do not simply address inequality through quick fix mechanisms; they challenge power relations and provoke sustainable changes to the structures of patriarchy. Overall, when framing indicators to measure gender equality and empowerment, there must be equal capability and access to opportunity and resources in conjunction with transformative agency and choice. Through this definition, a critique of each indicator illustrates that MDG3 is a narrow representation and measurement of gender equality and empowerment progress. The way in which MDG3 is framed fails to recognise diversity of experience and communicates progress as if all ascriptions are universally applicable. This sense of de-contextualisation de-legitimises proclamations of progress. 


\section{Eliminate Gender Disparity in Educational Enrolment}

Extensive research highlights the strong links between education, gender equality and empowerment outcomes. For example, education increases the likelihood that women will look after their own well-being and with that of their family. A study in Zimbabwe found education to be the primary factor that increased the likelihood of women accessing contraception and antenatal care, which improves maternal survival and well being (Kabeer 2003). Further, education can directly challenge and change power relations within the household. In Sierra Leone, educated women were found to have more leverage in bargaining in their household and to take more control over spending domestic income than uneducated women (Kabeer 2003). In this regard, increased enrolment is linked with better access to resources. It is wrong to assume, however, that an increase in enrolment for females will immediately correlate with the benefits such as those outlined. Despite its potential, how MDG3 frames the current education goal is narrow in scope and obfuscates contextual change. This can be illustrated through how it is measured.

Care must be used in interpreting measures of educational equality because perfect equality (1:1) may indicate equality of deprivation rather than equality of opportunity. An example is the case of Ethiopia, where there is only a 3 per cent difference between male and female secondary education enrolment figures. While there is close to parity between the sexes in secondary enrolment, the overall rate of enrolment is only 37.5 per cent (World Bank 2013). This indicates a problem of widespread educational deprivation, rather than an issue of equal access to opportunities. Further, studies suggest changes associated with education are conditioned by the context in which it is provided and the social relationships that it embodies and promotes (Kabeer 2005). For example, where women's role in society is defined purely in reproductive terms, education is seen in terms of equipping girls to be better wives and mothers, or increasing their chances of getting a suitable husband. These are legitimate aspirations, given the realities of society but they do not equip them with a sense of transformative agency that empowers them to question their subordinate status (Kabeer 2005). All these factors affect the transformative potential of education systems around the world. Despite these contextual variables, Sen and Mukherjee (2013) argue that gender equality in primary and secondary education has begun to epitomise the notion of gender equality and empowerment. Such a limited understanding represents limited progress from ways of thinking witnessed in previous decades. The importance of agency and choice, and recognising the shift in power relations between men and women, has become less important. The framing of MDG3 to measure gender equality purely through educational outcomes has caused it to revert back to merely meaning equality of achievement in meeting certain basic needs (Sen \& Mukherjee 2013). 
The limitations to education as a route to empowerment and equality do not negate the positive findings nor dismiss their inclusion in a gendered post2015 framework. While parity in access to schooling is the first step towards gender equality in education, it should not be assumed that its effects would be uniform across all contexts, nor should it be interpreted as a true reflection of development progress. The framing of global gender equality progress should move beyond simple quantitative data to include indicators such as rate of school completion. Despite being hard to measure, qualitative-based data, such as the quality of education and content of the curriculum, should be considered for a post-2015 framework. Such indicators are more likely to reflect challenges against existing patriarchal structures, thus better tracking overall progress on gender equality and empowerment. The level of educational attainment is also strongly linked to entry into the labour market.

\section{Increase the Share of Women in Non-Agricultural Wage Employment}

The rise of non-traditional agricultural export production in Africa and Latin America has led to a rise in wage employment for women in large-scale production units. Studies suggest that this income has induced a number of economic improvements for women and their families, including better control over how their money is spent (Kabeer 2005). For example, in Honduras, women working in maquiladoras (assembling manufactured goods for export) earned higher wages than workers elsewhere, and reported improvements in household relationships and help in domestic work from males. They were more likely to have voted in elections and to feel they carried some weight with the government (Hoyos et al. 2008). This case study reflects the potential for progress through access to opportunities and resources. The framing of this indicator of progress, however, also comes with widespread scepticism.

Firstly, this indicator only measures the presence or absence of work, and not the quality of work itself (Anker 2002 cited in Grown et al. 2005). Women's access to paid work can give them a greater sense of self-reliance, greater purchasing power and overall choice, but if it is undertaken in conditions that exploit their labour or health, its costs may outweigh its empowerment potential. Further, if the division of labour in domestic chores and child care is not renegotiated, such employment can become disempowering, as it becomes a 'double burden' in addition to women's pre-existing responsibilities. The International Labour Organization's (ILO) Decent Work agenda provides a framework for promoting access to employment and equal treatment. Indicators in this framework include gender-disaggregated unemployment rates, the female to male earnings ratio, and occupational segregation by sex. This comprehensive equality measurement should be considered for a post-2015 gender framework. Such an approach 
better highlights the contextual nature of gender equality. Framing gender equality progress through the increased participation of women in national parliaments has the potential for empowerment through transformative agency.

\section{Participation in National Parliaments}

As women represent half of the world's population, they should be entitled to equal representation in national parliaments. Such an achievement represents the most ambitious of the three forms of change singled out to measure progress on women's empowerment. Yet progress has been slow, with the percentage of parliamentary seats held by women increasing from 11.6 per cent in 1995 to only 19.7 per cent by January 2012 (UN 2012). This indicator is, however, correlated with various positive outcomes. For example, a study by Dollar et al. (2001 cited in Grown et al. 2005) found the quality of governance and the level of corruption fell in many countries as women's representation in national parliament increased. While this goal has great potential, the way in which it is framed de-politicises and simplifies the process in which women are moving into national parliaments.

At present, women who enter national parliaments are not generally drawn from the ranks of the poor, nor is there any guarantee that they are more responsive than men in parliament to the needs of poor women (Kabeer 2012, p. 21). Further, it is an imperfect proxy for tracking aggregate levels of female empowerment because it fails to examine whether women have power in national parliament to make decisions or choices. An increased female presence across governance structures clearly has the transformative potential to change unjust practices. But if the women are drawn from a narrow elite or have no constituency to which they must answer, their representation could be interpreted as token. Measuring the percentage of women in national parliaments should be accompanied by, and indeed built on, greater participation in local governance processes in a post-2015 framework. Evidence from India suggests that an increase of women in panchayats (local governance councils) has made women more likely to take advantage of state services and demand their rights, and also improved the provision of services for men (Chattopadhyay \& Duflo 2004). Further qualitative data, which measure female agency and influence to effect policy and outcomes, should be included.

This section argues that the framing of development progress under the heading of MDG3 de-contextualises and obfuscates the complex nature of gender equality. Fundamentally, this finding brings into question the legitimacy of progress proclaimed as part of the MDG banner. For example, an increase in women's access to education may improve their chance of a good marriage or their capacity to sign their name on a contract or document, but unless it 
provides them with the analytical capacity and courage to challenge unjust practices, its potential for transformative change is limited. The MDGs fail to highlight such important variables and real people are represented by abstract concepts and statistical figures to be moved up and down in the charts of progress. Given their potential for transformative change, however, these targets and indicators should not be abandoned when the MDGs expire in 2015. Rather, their definitions should be reconsidered and measurements improved to find a balance between the value of simplifying development for awareness purposes and recognising the complexities of development practice. Elements currently missing from MDG3 and newly proposed approaches to gender equality in the post-2015 era have been proposed to address this pervasive issue. The framing of such approaches is analysed in the next section.

\title{
Reframing a Gendered Post-2015 Framework
}

\begin{abstract}
Gender relations, like all social relations, are multi-stranded: they embody ideas, values, and identities; they allocate labour between different tasks, activities, and domains; they determine the distribution of resources; and they assign authority, agency, and decision-making power. This means that gender inequalities are multi-dimensional and cannot be reduced to some single and universally agreed set of priorities (Kabeer 2005: 22).
\end{abstract}

The year 2015 will be a time to evaluate the targets and indicators of progress articulated by the MDGs. It also presents as a chance to assess the adequacy and efficacy of MDG3. Reflecting upon Kabeer's (2005) statement above, a universally agreed upon set of priorities or strategies that address the issue of gender equality and empowerment is unlikely to be found. How progress on gender equality is reframed in the post-2015 era should seek to address the issues of legitimacy and oversimplification for which MDG3 can be criticised. In response, various new approaches have been proposed. This section first examines the inclusion of gender-based violence, an element said to be missing from MDG3, in a post-2015 framework. Secondly, it analyses the validity of framing gender equality through the proposed twin-track approach, which intends to mainstream gender across all post-2015 goals and be accompanied by another stand-alone goal.

\section{Gender-Based Violence}

It is estimated that gender-based violence is as serious a cause of death and incapacity among reproductive-age women as cancer; it is a more common cause of ill health among women than traffic accidents and malaria combined (Grown 
et al. 2005). It is recognised as a development constraint and its consequences are strongly linked to the desired outcomes of MDG3. For example, it affects children's schooling. A study in Nicaragua found that 63 per cent of children of female victims of violence had to repeat a school year and left school an average four years earlier than other children (Larraín et al. 1997 cited in Grown et al. 2005). Secondly, it has widespread economic multiplier effects. These include increased absenteeism, decreased labour market participation, reduced productivity, lower earnings and savings and lower intergenerational productivity (Grown et al. 2005). For example, it is estimated that in Chile domestic violence reduced women's earnings by $\$ 1.56$ billion in 1996, or more than 2 per cent of GDP (Morrison \& Biehl 1999). Violence against women restricts their ability to use their capabilities and take advantage of opportunities, thereby reinforcing gender inequality. Its inclusion in a post-2015 framework is questioned, however, because of the lack of reliable data and the difficulties associated with quantifying progress.

Accurate and reliable statistical data on gender-based violence is infrequent because of under-reporting by victims and under-recording by authorities (Grown et al. 2005). Thus, the collection of comparable data is rare. The state in many instances sees it as being beyond its scope of influence, as violence typically occurs within the private sphere. Elson and Balakrishnan (2012) argue that this attitude has led to the neglect of policy to eliminate genderbased violence against women in the past. A lack of data collection should not, however, be a barrier towards transformative action. The continual existence of such an epidemic fundamentally undermines both women's equality and empowerment. As such, its inclusion in a post-2015 framework is strongly validated. It is less clear how mitigation of such violence can be achieved and how it should be framed to truly reflect gender equality progress.

No single intervention will eliminate violence against women. A combination of statistical indicators associated with infrastructure, legal, judicial enforcement, education, health and other service-related actions can significantly reduce it and its consequences. For such action to be taken, violence against women must be universally viewed as unacceptable. Its inclusion in a post-2015 framework would be a vital step in acknowledging this. The framing of such an issue should be reflected in the statistics outlined above, but accompanied by universally agreed upon data collection methods and research. Currently, the inclusion of gender-based violence in the post-2015 agenda does not directly challenge any of the criticisms associated with the de-contextualisation and oversimplification of gender equality as highlighted under MDG3. Given the lack of statistical reliability, if such diverse methods are not adopted, the complexities of genderbased violence are in danger of being subject to the same issues of obfuscating 
progress as witnessed under MDG3. In responding to criticisms centred on MDG3, strong advocates propose a twin-track approach to gender equality in the post-2015 era.

\section{A Twin-Track Approach}

A twin-track approach to a post-2015 framework combines a stand-alone goal of gender equality with gender mainstreamed across all other objectives. Smee and Woodroffe (2013: 22), representing the Gender and Development Network, argue that this approach is the most likely to address the widespread structural inequalities, which persist for women and girls, and address issues associated with the oversimplification and de-contexualising nature of MDG3. A standalone goal on gender equality is undoubtedly necessary because gender equality is a goal in itself, deserving both focused political and financial commitment. Whilst its underlying goals and indicators must be reframed to better reflect contextual development progress, a stand-alone goal on gender provides clear lines of responsibility and a key advocacy lever for civil society to hold their national governments to account.

As an alternative to the twin-track approach, it has been proposed that gender equality should be grouped under a general inequalities theme across all new goals (Smee \& Woodroffe 2013). Arguably, this strategy would undermine gender equality advocacy and would result in the scaling back of resources and political commitments (Spieldoch 2013). Although this may be true, gender mainstreaming has been widely criticised. Grown et al. (2005) argue that gender indicators that crosscut each goal are supposed to be everyone's business, but they tend to become no one's responsibility. This could lead to a lack of internal responsibility, an absence of accountability mechanisms, as well as resistance within organisational culture. Perhaps the main consequence of a mainstreaming agenda is that the guidelines for gender mainstreaming become an end in themselves rather than a process. This issue of policy evaporation could become a legitimate risk post-2015, as gender mainstreaming could become simply another requirement of funding. Advocates who propose the approach currently lack strong evidence to suggest this gender mainstreaming initiative would be successful and would challenge issues of de-contextualisation. Many seem more set on raising the profile of gender inequality through mainstreaming, without considering its potential negative consequences. Rather than gender becoming overtly mainstreamed across all goals, better collection and analysis of sex-disaggregated data underpinning each new target should be the priority. This should be accompanied by a standalone goal with reframed indicators, which focuses on the need to promote linkages with other global development objectives. 


\section{Conclusion}

This essay argues that the framing of MDG3 to measure development progress obscures and oversimplifies the contextual nature of gender inequality. The indicators of progress adopted as part of MDG3: eliminating gender disparity in educational enrolment, increasing the share of women in non-agricultural wage employment and increasing the proportion of seats held by women in national parliaments, do have the potential to promote gender equality and empowerment. They are framed, however, through a set of reductionist variables that fundamentally obscure the development reality. The reframing of the post-2015 framework should build on the strengths of the current framework to find a balance between simplicity of communication for awareness purposes, while highlighting the complex and contextual nature of gender equality. Although important, the inclusion of gender-based violence as a post-2015 progress indicator does not directly challenge any of the criticisms currently underpinning MDG3. The lack of reliable statistical data suggests that the inclusion of this issue will inevitably be subject to similar criticisms of MDG3 to do with legitimacy and de-contextualisation. Additionally, the twintrack approach seems set on raising the profile of gender inequality through mainstreaming, yet does not challenge the issue of obfuscation. If direct efforts towards addressing such issues in policy formulation are not addressed, development progress will continue to be premised upon a de-contextualised and de-legitimatised definition of gender inequality.

MDG3 has been invaluable for the global gender equality movement. It has rallied unprecedented financial and political support, and introduced universally endorsed indicators that do have the potential to reduce inequality and enable empowerment. It is important, however, to remember the critical importance of this new framework for millions of women around the world who are subject to daily deprivation caused by gender inequality. Currently, the framing of MDG3 obscures the reality of such deprivation.

\section{Bibliography}

Chattopadhyay, R \& Duflo, E 2004, 'Women as Policy Makers: Evidence from a Randomized Policy Experiment in India', Econometrica, vol. 72, no. 5, pp. 1409-443.

Clemens, MA, Kenny, CJ \& Moss, TJ 2007, 'The Trouble with the MDGs: Confronting Expectation of Aid and Development Success', World Development, vol. 35, no. 5, pp. 735-51. 
Elson, D \& Balakrishnan R 2012, 'The Post-2015 Development Framework and the Realization of Women's Rights and Social Justice', Center for Women's Global Leadership, Rutgers, The State University of New Jersey.

Fukuda-Parr S, Greenstein J \& Stewart, D 2013, 'How Should MDG Success and Failure be Judged: Faster Progress or Achieving the Targets?', World Development, vol. 41, pp. 19-30.

Grown, C, Gupta, GR, Khan, Z 2003, ‘Promises to Keep: Achieving Gender Equality and the Empowerment of Women', A Background Paper for the Task Force on Education and Gender Equality of the Millennium Project, International Center for Research on Women, Washington DC.

Grown, C, Gupta, GR \& Aslihan, K 2005, ‘Taking Action: Achieving Gender Equality and Empowerment', UN Millennium Project: Taskforce on Education and Gender Equality, UNDP, Earthscan, London.

Hoyos, RE, Bussolo, M \& Núñez, O 2008, ‘Can Maquila Booms Reduce Poverty? Evidence from Honduras', Policy Research Working Paper, no. 4789, World Bank Development Economics Prospect Group.

Hulme, D \& Fukuda-Parr, S 2009, 'International Norm Dynamics and "the End of Poverty": Understanding the Millennium Development Goals (MDGs)', BWPI Working Paper 96, Brooks World Poverty Institute, The University of Manchester.

Kabeer N 2003, 'Gender Equality, Poverty Eradication and the Millennium Development Goals: Promoting Women's Capabilities and Participation', Gender and Development, Discussion Paper no. 13, Economic and Social Commission for Asia and the Pacific.

— 2005, 'Gender Equality and Women's Empowerment: A Critical Analysis of the Third Millennium Development Goal', Gender and Development, vol. 13, no. 1, pp. 13-24.

Malhorta, A, Schuler, SR \& Boender, C 2002, 'Measuring Women's Empowerment as a Variable in International Development', Gender and Development Group, World Bank.

Morrison, A \& Biehl, L (eds) 1999, ‘Too Close to Home: Domestic Violence in Latin America', Inter-American Development Bank, Washington DC.

Organisation for Economic Co-operation and Development (OECD) 2013, 'Unfinished Business - Women and Girls Front and Centre Beyond 2015', OECD DAC Network on Gender Equality, Paris, viewed May 4 2013, <http:// www.oecd.org/dac/gender>. 
Sen, G \& Mukherjee, A 2013, No Empowerment without Rights, No Rights without Politics: Gender-Equality, MDGs and the post 2015 Development Agenda, Working Paper Series: The Power of Numbers, A Critical Review of MDG Targets for Human Development and Human Rights, Harvard School of Public Health, Boston.

Smee, S \& Woodroffe, J 2013, Achieving Gender Equality and Women's Empowerment in the Post-2015 Framework, Global Thematic Consultation, The Gender and Development Network, London, viewed 3 May 2013, $<$ www.gadnetwork.org.uk $>$.

Spieldoch, A 2013, 'Gender Equality in the Post-2015 Agenda: Where Does it Stand?', Heinrich Böll Stiftung, Washington DC, viewed May 14 2013, $<$ www.us.boell.org $>$.

United Nations Development Fund for Women (UNIFEM) 2012, Violence Against Women, UN Women, viewed 16 May 2013, <http://www.unifem.org/ gender_issues/violence_against_women/>.

United Nations (UN) 2000, United Nations Millennium Declaration, Resolution Adopted by the General Assembly, 56th Session, Agenda Item 60 (b), 18 September.

2005, In Larger Freedom: Towards Development, Security, and Human Rights For All, Report of Secretary General, 59th Session, Agenda Item 45 and 55, 21 March.

2012, 'The Millennium Development Goals Report', New York.

World Bank 2013, World Development Indicators: Ethiopia, World Bank Group, viewed 18 May 2013, <http://data.worldbank.org/country/ethiopia>. 
This text taken from The ANU Undergraduate Research Journal Volume Five 2013, published 2014 by ANU Press, The Australian National University, Canberra, Australia. 